$$
\begin{aligned}
& \text { ANL/ET/CP-94259 } \\
& \text { CONF-9710120-- }
\end{aligned}
$$

\title{
CERAMIC COMPOSITES: ROLES OF FIBER AND INTERFACE*
}

\author{
J. P. Singh and D. Singh \\ Energy Technology Division \\ Argonne National Laboratory \\ Argonne, Illinois 60439 USA
}

September 1997

The submitted manuscript has been created
by the University of Chicago as Operator of
Argonne National Laboratory ("Argonne")
under Contract No. W-31-109-ENG-38 with
the U.S. Department of Energy. The U.S.
Government retains for itsell, and others act-
ing on its behall, a paid-up, nonexclusive,
irrevocable worldwide license in said article
to reproduce, prepare derivative works, dis-
tribute copies to the public, and pertorm pub-
licly and display publicly, by or on behalf of
the Government.

D'STRIEUTION OF THIS DOCURERT IS URUMATED of
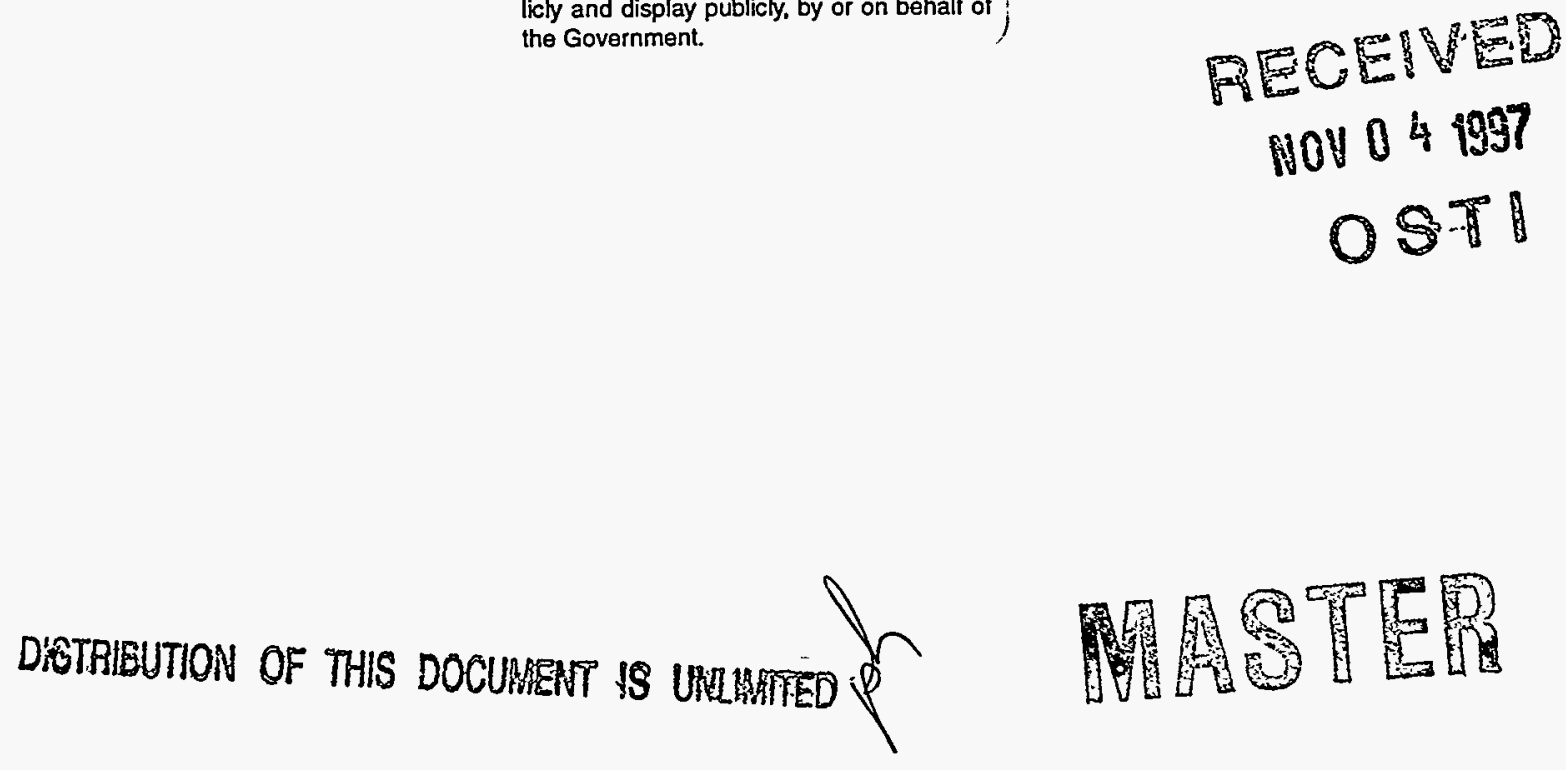

Invited paper to be submitted to Topical Workshop on Ceramic Matrix Composites, Tokyo, October 28-31, 1997.

*Work supported by the U.S. Department of Energy, Advanced Research and Technology Development, Fossil Energy Material Program, and Office of Industrial Technology, Energy Efficiency and Renewable Energy, under Contract W-31-109-Eng-38. 


\section{DISCLAIMER}

This report was prepared as an account of work sponsored by an agency of the United States Government. Neither the United States Government nor any agency thereof, nor any of their employees, makes any warranty, express or implied, or assumes any legal liability or responsibility for the accuracy, completeness, or usefulness of any information, apparatus, product, or process disclosed, or represents that its use would not infringe privately owned rights. Reference herein to any specific commercial product, process, or service by trade name, trademark, manufacturer, or otherwise does not necessarily constitute or imply its endorsement, recommendation, or favoring by the United States Government or any agency thereof. The views and opinions of authors expressed herein do not necessarily state or reflect those of the United States Government or any agency thereof. 


\section{DISCLAIVIXR}

Portions of this document may be Illegible in electronic image products. Insges are produced from the best available original document. 


\title{
CERAMIC COMPOSITES: ROLES OF FIBER AND INTERFACE
}

\author{
J. P. Singh and D. Singh \\ Energy Technology Division \\ Argonne National Laboratory \\ Argonne, Illinois 60439 USA
}

Key Words: composites, in-situ fiber strength, residual stress, interface

\begin{abstract}
Results are presented that elucidate (a) the effects of fiber coating on retained fiber strength and mechanical properties of Nicalon-fiber-reinforced SiC matrix composites, and (b) the role of residual stresses in the interfacial bond strength of SiC-fiber-reinforced reaction-bonded $\mathrm{Si}_{3} \mathrm{~N}_{4}$ matrix composites. For Nicalon-fiber-reinforced $\mathrm{SiC}$ matrix composites that were fractured in a flexural mode, retained in-situ fiber strength, ultimate strength, and work-of-fracture (WOF) of the composites increased with increasing thickness of the fiber coating and reached maximum values at a coating thickness of $\approx 0.3 \mu \mathrm{m}$. A direct correlation between the variation of in-situ fiber strength and the variation of ultimate strength and WOF of the composites clearly indicates the critical role of the retained in-situ strength of reinforcing fibers in composites. Fiber pushout tests performed on $\mathrm{SiC}$-fiber-reinforced reaction-bonded $\mathrm{Si}_{3} \mathrm{~N}_{4}$ matrix composites indicate that both debonding and frictional shear stresses decreased with increasing fiber content. These variations are consistent with the variation of residual radial stress on fibers, as measured by neutron diffraction, i.e., residual stresses decreased with increasing fiber content. Because fracture behavior is strongly controlled by interfacial bond strength, which is proportional to the residual radial stress, appropriate control of residual stresses is critical in the design of composites with desired fracture properties.
\end{abstract}




\section{Introduction}

Continuous-fiber ceramic composites (CFCCs) are candidate materials for structural applications in various industries, including automotive, aerospace, and utilities, primarily because of their improved flaw tolerance, large work of fracture (WOF), and noncatastrophic mode of failure.1,2 The mechanical behavior of these composites is greatly influenced by the strength of the reinforcing fibers, the characteristics of fiber/matrix interface, and the residual stresses due to thermal expansion mismatch between fibers and matrix. Fiber strength is an important parameter that controls the fracture behavior of CFCCs. High strength of reinforcing fibers is critical because once a matrix crack is initiated and extended, load is transferred from the matrix to the fibers in the wake of the crack. Weak fibers fracture and lead to catastrophic failure of the composite, whereas strong fibers accommodate the stresses. Theoretical analysis and experimental observation have shown that the amount of fiber pullout (which contributes to the toughening of a composite) is strongly influenced by the mean strength and the variability in strength of the reinforcing fibers. ${ }^{3}$ Also, the ultimate load-bearing capacity of the composite is determined by fiber strength characteristics. ${ }^{4}$

The strength of the fiber/matrix interface bond should be optimized to facilitate desired fiber pullout during composite fracture, this in turn will lead to substantial energy dissipation and improved fracture toughness. Bond strength is controlled by both interfacial characteristics and residual stresses induced by thermal expansion mismatch between fibers and matrix and can be tailored by appropriately coating the fiber surface. Fiber coating not only controls bond strength but also protects the fiber from being damaged by flaws generated during processing and service. Therefore, an improved understanding of the role of fiber coating and residual stresses in fracture behavior will lead to the design and processing of CFCCs with reliable performance. In this paper, we present results that will elucidate, (1) the effects of fiber coating on flaw generation, retained fiber strength, and mechanical properties of Nicalon-fiber-reinforced $\mathrm{SiC}$ matrix 
composites and (2) the role of residual stresses in the interfacial bond strength of SiC-fiberreinforced reaction-bonded $\mathrm{Si}_{3} \mathrm{~N}_{4}$ matrix composites.

\section{Specimens and Experimental Procedure}

To evaluate the effects of fiber coating, specimens of Nicalon-fiber-reinforced $\mathrm{SiC}$ matrix composites with approximately $42 \mathrm{vol} . \%$ fiber reinforcements and carbon interlayer coating of varying thickness $(0-1.25 \mu \mathrm{m})$ were obtained from Oak Ridge National Laboratory. The specimens were fabricated by densifying multiple layers of Nicalon mats stacked in a graphite die. Chemical vapor infiltration (CVI), under forced conditions of thermal and pressure gradients, was used to densify the preforms with SiC. The resulting composites were close to $90 \%$ dense. Details of composite specimen fabrication are described elsewhere. 5,6

The role of residual stresses in controlling the fiber/matrix interfacial bond strength was evaluated by using unidirectional monofilament $\mathrm{SiC}$-reinforced reaction-bonded silicon nitride (RBSN) composite specimens that were fabricated at the NASA Lewis Research Center, Cleveland, OH. Commercially available uncoated (SCS-0) or carbon-coated (SCS-6) SiC monofilaments (Textron Specialty Materials Division, Lowell, MA) were used as reinforcements. These monofilaments consist of a central carbon core, $33 \mu \mathrm{m}$ in diameter, an intermediate layer of chemical-vapor-deposited $\mathrm{SiC}$, and an optional outer 3- $\mu \mathrm{m}$-thick carbonrich double coating, resulting in an overall filament diameter of $\approx 142 \mu \mathrm{m}$. Composites were fabricated by high-temperature consolidation and nitridation of alternately stacked $\mathrm{SiC}$ fiber mats and silicon cloth in a die. The details of the processing are described in Ref. 7. Composite specimens with varying fiber content were processed to change the interfacial residual stress. The effects of the changes in residual stress were estimated by measuring interfacial bond strength using fiber pushout tests.

The fiber pushout testing followed the procedure described by Bright et al. ${ }^{8}$ Pushout specimens, $\approx 1-4 \mathrm{~mm}$ thick, were cut normal to the fiber axis. The faces normal to the fiber axis 
were ground flat and parallel to each other. Subsequently, one face was fine-polished to a 0.25 $\mu \mathrm{m}$ surface finish. These specimens were mounted on a specimen holder with an $\approx 0.8$-mm-wide slot to allow the exit of fiber that is pushed out from the other end. The sample holder was fixed to an $\mathrm{X}-\mathrm{Y}$ micropositioning stage and the whole assembly was attached to a load cell mounted on the crosshead of a mechanical testing machine (Model 4505, Instron Corporation, Canton, MA). The pushout tests involved positioning of individual fibers (with the X-Y stage, as described in Ref. 8) under an $\approx 60-\mu \mathrm{m}$-diameter flat tip tungsten carbide indenter fixed to the top plate of the mechanical tester, followed by loading the fibers at a displacement rate of $0.05 \mathrm{~mm} / \mathrm{min}$. The load-displacement plots were recorded and the debonding and frictional shear stresses were calculated from the corresponding load and interface area. For each composite, 15-20 fibers were pushed out to account for the statistical variation in the local response of the materials.

Ultimate strength and WOF of Nicalon-fiber-reinforced SiC matrix composites with fiber coating of varying thickness were obtained by fracturing composites in a four-point-bend mode on the mechanical testing machine with inner and outer loading spans of 15 and $30 \mathrm{~mm}$, respectively. The flexure bar specimens were typically $3 \times 4 \times 32 \mathrm{~mm}$ and they were loaded at a rate of $1.27 \mathrm{~mm} / \mathrm{min}$ under ambient conditions. The ultimate stress was determined from the peak load obtained from the load-vs.-specimen-displacement plot. The WOF of the composites was estimated from the area under the load-vs.-specimen-displacement plots, normalized on the basis of unit cross-sectional area of the fractured composites. The true specimen displacement was obtained by subtracting the system displacement from the total displacement. The system displacement was determined by measuring system compliance with the aid of a stiff alumina piece.

Fractured composite specimens were examined with a scanning electron microscope (Model JXA-840A, JEOL Co., Ltd., Tokyo) to locate the failure origin and establish the associated characteristic fracture surface morphology of the fibers to estimate in-situ fiber strength. 


\section{Results and Discussion}

Figure 1 shows the variation in fracture stress (i.e., ultimate strength) with fiber coating thickness. The ultimate strength increases with the coating thickness and reaches a peak value of $380 \mathrm{MPa}$ at a coating thickness of $\approx 0.2-0.6 \mu \mathrm{m}$. Further increase in coating thickness did not significantly affect the ultimate strength. A plot of WOF as a function of coating thickness, presented in Fig. 2, shows that WOF increases rapidly with fiber coating thickness and reaches a peak value of $1.92 \times 10^{4} \mathrm{~N}-\mathrm{m} / \mathrm{m}^{2}$ at a coating thickness of $\approx 0.13-0.3 \mu \mathrm{m}$. The WOF did not change significantly with further increase in coating thickness.

Scanning electron microscopy (SEM) of the fracture surfaces of composites reinforced with fibers with and without carbon coatings revealed differences in their fracture surface morphology as shown in Fig. 3. In Fig. 3a, the fracture surface of composites with no fiber coating shows brittle failure without fiber pullout. On the other hand, Fig. $3 \mathrm{~b}$ indicates substantial fiber pullout for composites with coated fibers. These observations are consistent with load-displacement behavior for the two types of composites. For the coated fiber-reinforced composites, the load gradually decreased after the peak load was reached. On the other hand, the uncoated, fiberreinforced composites showed an instantaneous drop at the peak load.

In-situ fiber strength of the composites was evaluated from the characteristic markings on the fracture surface of the fibers in a Nicalon-fiber-reinforced $\mathrm{SiC}$ composite, tested in the fourpoint-bend mode, as shown in Fig. 4. Characteristic features associated with brittle failure, such as mirror (smooth region around the fracture origin) and hackle (region of multiple fracture planes) are clearly observable on the surface of fractured fibers. SEM of the fibers showed that most failed from defects or flaws on the fiber surface. Using the measured values of mirror radii, we estimated the tensile strength of the fibers from the following empirical relationship, which is commonly used for ceramics: 9,10

$$
\sigma_{\mathrm{f}} \mathrm{r}_{\mathrm{m}}^{1 / 2}=\mathrm{A}_{\mathrm{m}}
$$


where $r_{m}$ represents the mirror radius, $\sigma_{f}$ is the tensile strength, and $A_{m}$ is the mirror constant, which is related to the fracture toughness of the material. In the present study, $A_{m}$ is taken as 3.5 $\mathrm{MPam}^{1 / 2}$, following the work of Thouless et al. ${ }^{11}$ The strength of more than 30 Nicalon fibers for each set of composite specimens was determined by measuring their fracture mirror radius and solving Eq. 1 .

The strength distribution of fibers in the composites was described by the Weibull function given by Eq. 2,

$$
\mathrm{F}(\sigma)=1-\exp \left[-\left(\frac{\sigma}{\sigma_{\mathrm{o}}}\right)^{\mathrm{m}}\right]
$$

In Eq. 2, $\mathrm{F}$ is the fracture probability at a given stress $\sigma, \mathrm{m}$ is the Weibull modulus that characterizes the flaw size distribution in the fibers, and $\sigma_{0}$ is the scale parameter that signifies a characteristic strength value of the fibers.

The variation of in-situ fiber strength (scale parameter, $\sigma_{0}$ ) as a function of coating thickness is shown in Fig. 5, which clearly shows that fiber strength initially increases with coating thickness and reaches a peak value at a coating thickness in the range of $\approx 0.13-0.6 \mu \mathrm{m}$. We believe that the initial increase in strength is due to protection of the fiber by the coating, which minimizes fiber surface damage during processing and fabrication. Further increase in coating thickness does not increase the effectiveness of the coating in protecting the fiber from damage. This result has very important implications for the determination of optimum fiber coating parameters and composite processing.

A comparison of Figs. 1 and 2 with Fig. 5 shows a direct correlation between the in-situ fiber strength, and ultimate strength and WOF of composites with varying coating thickness. These observations suggest a strong dependence of ultimate strength and WOF on in-situ fiber strength characteristics. In addition, fiber coating may also partly result in improved fiber/matrix interfacial characteristics that lead to the observed increase in both ultimate strength and WOF. 
A typical load-vs.-displacement plot for the fiber pushout experiment, performed on RBSN specimens, is shown in Fig. 6. Initially, load increases and reaches a maximum value $P_{d}$, at which fiber/matrix debonding initiates and is indicated by instantaneous load drop. At this point the fiber/matrix interface may be either partially or completely debonded. With further displacement, the load increases because of additional debonding and frictional siding and reaches a value $P_{\max }$. At this point, the entire fiber is debonded and begins to slide out the other side of the matrix, indicated by a steady decrease in load.

Assuming a uniform distribution of stress along the embedded fiber length $L$, the debonding $\tau_{\mathrm{d}}$ and interfacial frictional $\tau_{\mathrm{f}}$ stresses were calculated by the following equations

$$
\tau_{\mathrm{d}}=\mathrm{P}_{\mathrm{d}} / 2 \pi \mathrm{aL} \text { and } \tau_{\mathrm{f}}=\mathrm{P}_{\max } / 2 \pi \mathrm{aL},
$$

where $\mathrm{a}$ is the fiber radius. The variation of debonding and interfacial shear stresses as a function of fiber content, shown in Fig. 7, indicates that both debonding and shear stresses decrease with increasing fiber content, except for the composites with a fiber content of $8.4 \mathrm{vol} . \%$. The debonding and shear stresses are lower for composites with 8.4 vol.\% fiber than for composites with 12.6 vol.\% fiber. This inconsistency in the trend of stress variation is believed to be related to processing. A density measurement by Archimedes' method indicates a lower density ( $70 \%$ of theoretical) for composites with 8.4 vol.\% fiber than the density ( $76 \%$ of theoretical) of composites with 12.6 vol.\% fiber.

The general trend of decrease in debonding and interfacial shear stresses with fiber content is consistent with the predicted variation of residual stresses on the fibers due to the expansion mismatch between the fiber and the matrix. As reported in Refs. 8 and 12, the thermal expansion coefficient of an RBSN matrix $\left(\alpha_{\mathrm{m}}\right)$ is $3.3 \times 10^{-6} /{ }^{\circ} \mathrm{C}$ whereas the expansion coefficients of a SiC

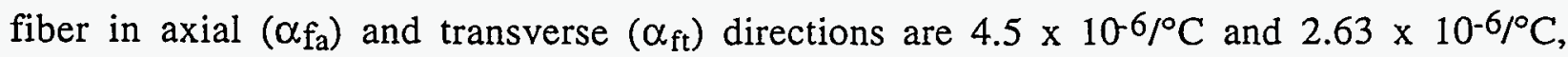
respectively. Based on these expansion coefficients, it is expected that, during cooling of composites from processing temperature, the fibers will be subjected to tensile axial and 
compressive transverse (radial) stresses. The compressive radial stresses on the fiber will directly contribute to frictional shear stress at the interface. Hence, any change in residual radial stress will cause a variation in interfacial bonding and shear stresses.

Figure 8 shows a variation in axial and transverse (radial) residual strains in $\mathrm{SiC}$ fibers that were measured ${ }^{13}$ by neutron diffraction in the Intense Pulsed Neutron Source at Argonne National Laboratory. These strains were measured as a function of fiber content in SiC/RBSN composites. It can be clearly seen in the figure that transverse (radial) compressive strain decreases with increasing fiber content, a finding that agrees with the analytical prediction of Majumdar et al. 14 The observed decrease in the transverse strain will result in a corresponding decrease in transverse stress, which, in turn, will lead to reduced interfacial shear stress. These predictions, based on the measured residual strain in composites by neutron diffraction, confirm the interfacial bonding and frictional shear stresses obtained during fiber pushout testing.

\section{Summary}

1. Processing-induced damage of Nicalon fibers can be minimized by the application of a carbon coating, which leads to a corresponding increase in the retained in-situ strength of the fibers during composite processing.

2. Ultimate strength and work of fracture (WOF) of composites were found to increase with increasing coating thickness up to $\approx 0.3 \mu \mathrm{m}$. Further increase in coating thickness did not significantly affect mechanical properties, indicating an optimum coating thickness for processing.

3. A similarity between the dependence of in-situ fiber strength, ultimate strength, and WOF on fiber coating thickness suggests a direct correlation between retained in-situ fiber strength and resulting mechanical properties. 
4. The increase in ultimate strength and WOF with increasing fiber coating thickness may also be partly due to improved fiber/matrix interfacial characteristics.

5. For $\mathrm{SiC}$-fiber-reinforced reaction-bonded $\mathrm{Si}_{3} \mathrm{~N}_{4}$ matrix composites, both debonding and frictional shear stresses generally decreased with increasing fiber content. These variations are consistent with the variations in residual radial stress of fibers measured by neutron diffraction; the latter decreased with increasing fiber content.

\section{Acknowledgments}

Work supported by the U.S. Department of Energy, Advanced Research and Technology Development, Fossil Energy Material Program, and Office of Industrial Technology, Energy Efficiency and Renewable Energy, under Contract W-31-109-Eng-38. The authors thank R. A. Lowden (Oak Ridge National Laboratory) for providing Nicalon-fiber-reinforced $\mathrm{SiC}$ matrix composites, Ramakrishna T. Bhatt (U.S. Army Propulsion Directorate, NASA Lewis Research Center) for providing SiC/RBSN composites, and Grant Pollard for providing experimental assistance.

\section{References}

1. D. B. Marshall and A. G. Evans, "Failure Mechanisms in Ceramic-Fiber/Ceramic Matrix Composites," J. Am. Ceram. Soc., 68 [5] 225-231 (1985).

2. A. G. Evans and D. B. Marshall, "The Mechanical Behavior of Ceramic Matrix Composites," Overview No. 85, Acta Metall., 37 [10] 2567-2583 (1989).

3. M. D. Thouless, O. Sbaizero, L. S. Sigl, and A. G. Evans, "Effect of Interface Mechanical Properties on Pullout in a SiC-Fiber-Reinforced Lithium Aluminum Silicate Glass Ceramic," J. Am. Ceram. Soc., 72 [4] 525-532 (1989). 
4. T. Mah, M. G. Mendiratta, A. P. Katz, R. Ruh, and K. S. Mazdiyasni, "Room Temperature Mechanical Behavior of Fiber-Reinforced Ceramic Matrix Composites," J. Am. Ceram. Soc., 68 [1] C-27 - C-30 (1985).

5. D. P. Stinton, A. J. Caputo, and R. A. Lowden, "Synthesis of Fiber-Reinforced SiC Composites by Chemical Vapor Infiltration," Am. Ceram. Soc. Bull., 65 [2] 347-350 (1986).

6. D. P. Stinton, T. M. Bessman, and R. A. Lowden, "Advanced Ceramics by Chemical Vapor Deposition Techniques," Am. Ceram. Soc. Bull., 67[2] 350-355 (1988).

7. R. T. Bhatt, "Method of Preparing Fiber-Reinforced Ceramic Materials," U.S. Patent No. 4689188.

8. J. D. Bright, D. K. Shetty, C. W. Griffin, and S. Y. Limaye, "Interfacial Bonding and Friction in Silicon Carbide (Filament)-Reinforced Ceramic- and Glass-Matrix Composites," J. Am. Ceram. Soc., 72[10] 1891-98 (1989).

9. H. P. Kirchner and R. M. Gruver, "Fracture Mirror in Alumina Ceramics," Phil. Mag., 27 1433-1446 (1973).

10. J. J. Mecholsky, S. W. Freiman, and R. W. Rice, "Fracture Surface Analysis of Ceramics," J. Mater. Sci., 11 1310-1319 (1976).

11. M. D. Thouless, O. Sbaizero, L. S. Sigl, and A. G. Evans, "Effect of Interface Mechanical Properties on Pullout in a SiC-Fiber-Reinforced Lithium Aluminum Silicate Glass Ceramic," J. Am. Ceram. Soc., 72 [4] 525-532 (1989).

12. R. W. Goettler and K. T. Faber,"Interfacial Shear Stresses in $\mathrm{SiC}$ and $\mathrm{Al}_{2} \mathrm{O}_{3}$ FiberReinforced Glasses," Ceram. Eng. Sci. Proc., 9[7-8] 861-701 (1988). 
13. A. Saigal, D. S. Kupperman, J. P. Singh, D. Singh, J. Richardson, and R. T. Bhatt, "Thermal Residual Strains and Stresses in Silicon-Carbide-Fiber-Reinforced Silicon Nitride Composites," Compos. Eng., 3[11] 1075-1086 (1993).

14. S. Majumdar, D. Singh, and J. P. Singh, "Analysis of Pushout Tests on a SiC-FiberReinforced Reaction-Bonded $\mathrm{Si}_{3} \mathrm{~N}_{4}$ Composite," Compos. Eng., 3[4] 287-312 (1993). 


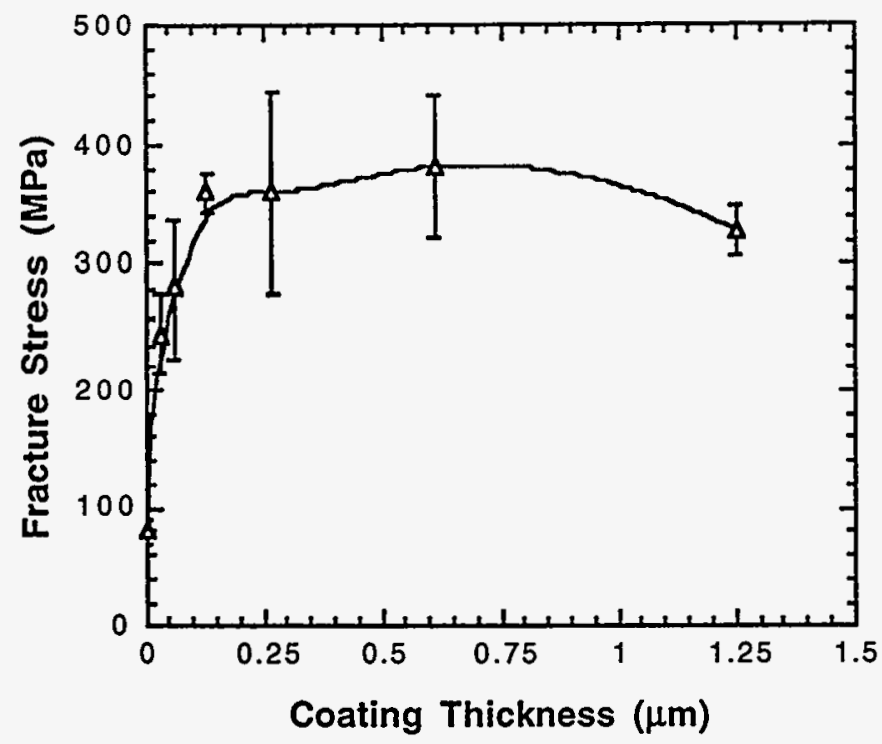

Fig. 1. Dependence of fracture stress on fiber coating thickness.

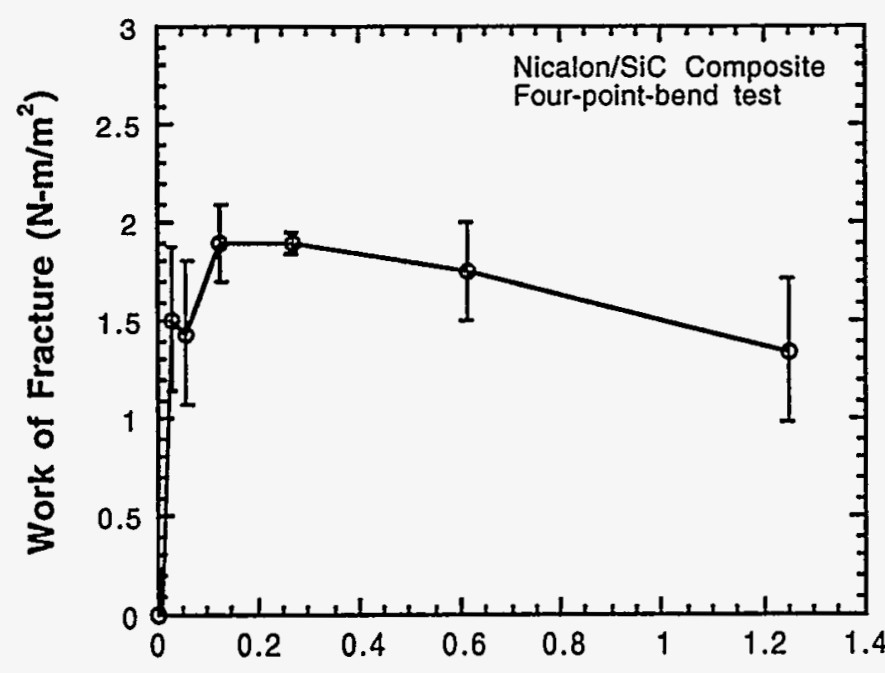

Fiber Coating Thickness ( $\mu \mathrm{m})$

Fig. 2. Dependence of work-of-fracture on fiber coating thickness. 


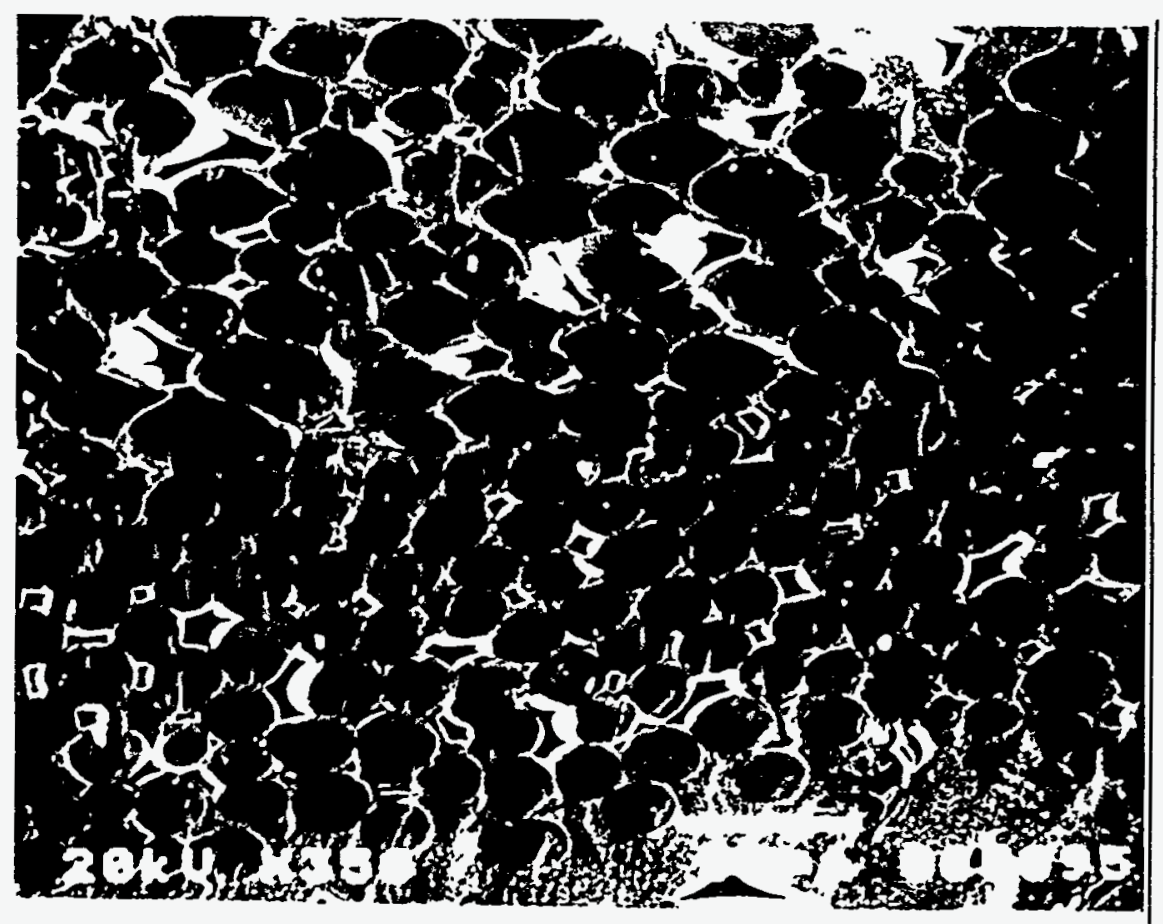

(a)

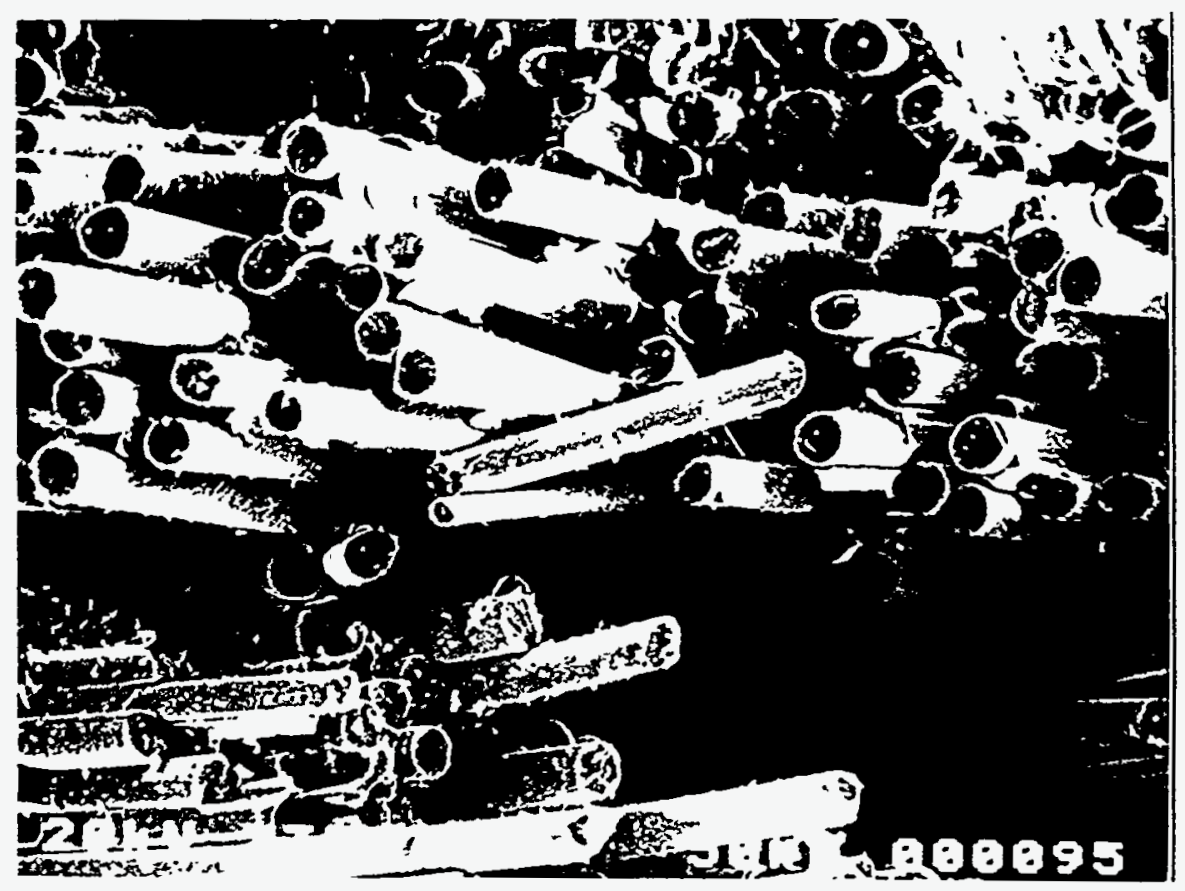

(b)

Fig. 3. Typical fracture surface of CVI SiC/SiC composites reinforced with (a) uncoated fibers and (b) coated fibers. 


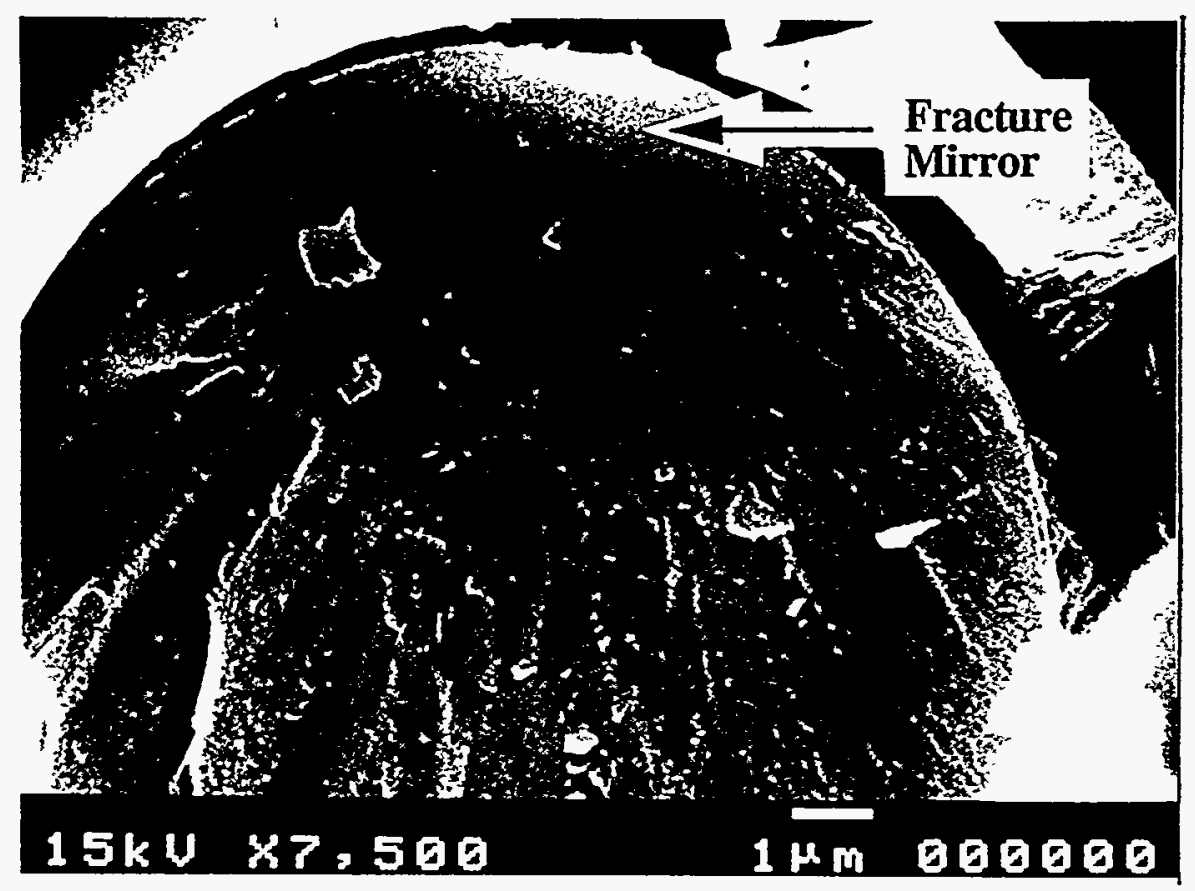

Fig. 4. Photomicrograph of surface morphology of fractured fiber in a CVI SiC/SiC composite.

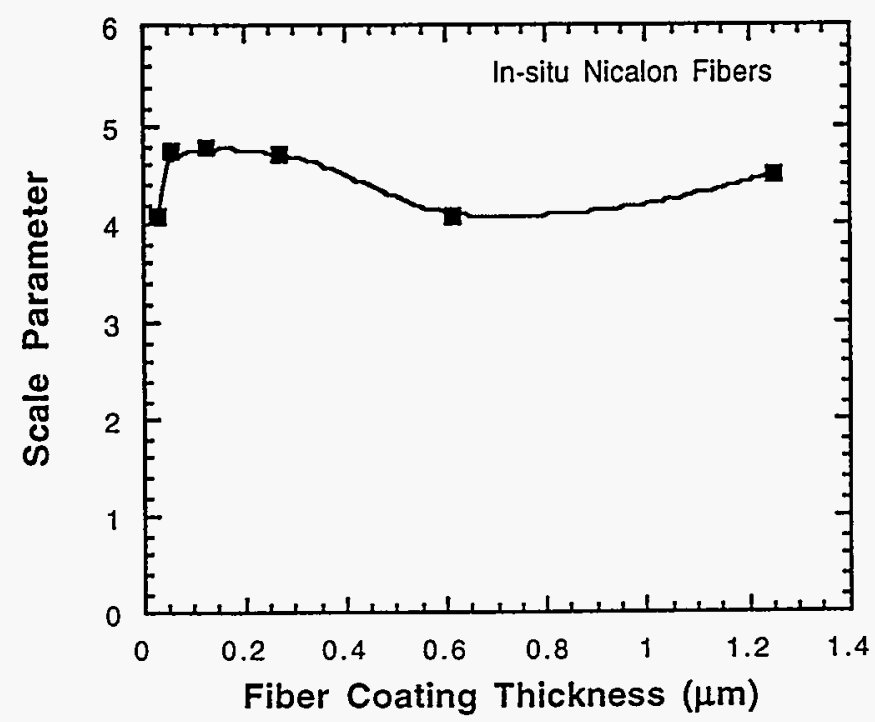

Fig. 5. Dependence of in-situ fiber strength on fiber coating thickness. 


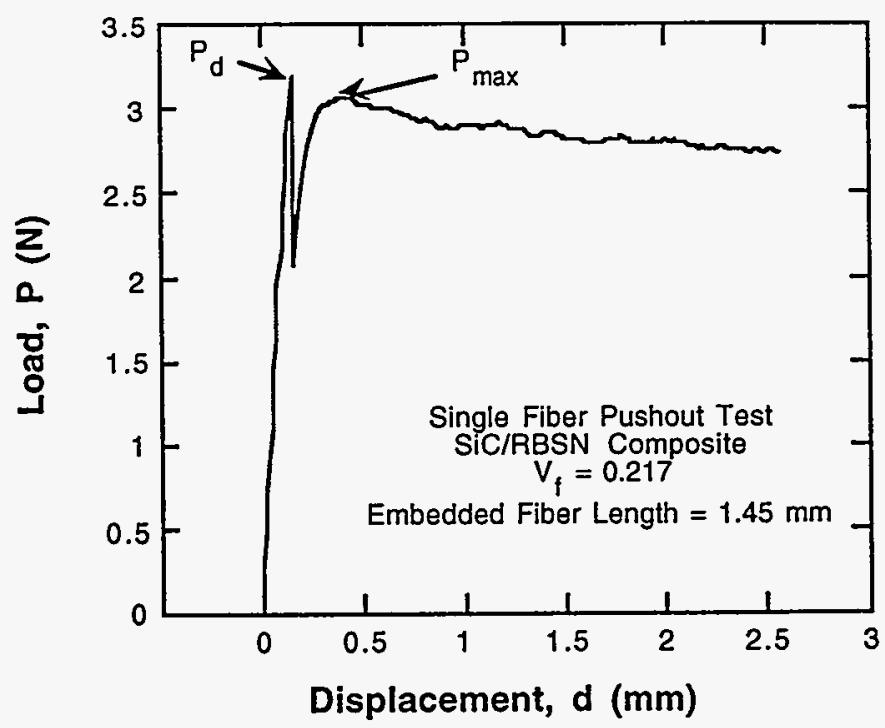

Fig. 6. Typical load-displacement plot for fiber pushout test, showing $P_{d}$ and $P_{\max }$. 


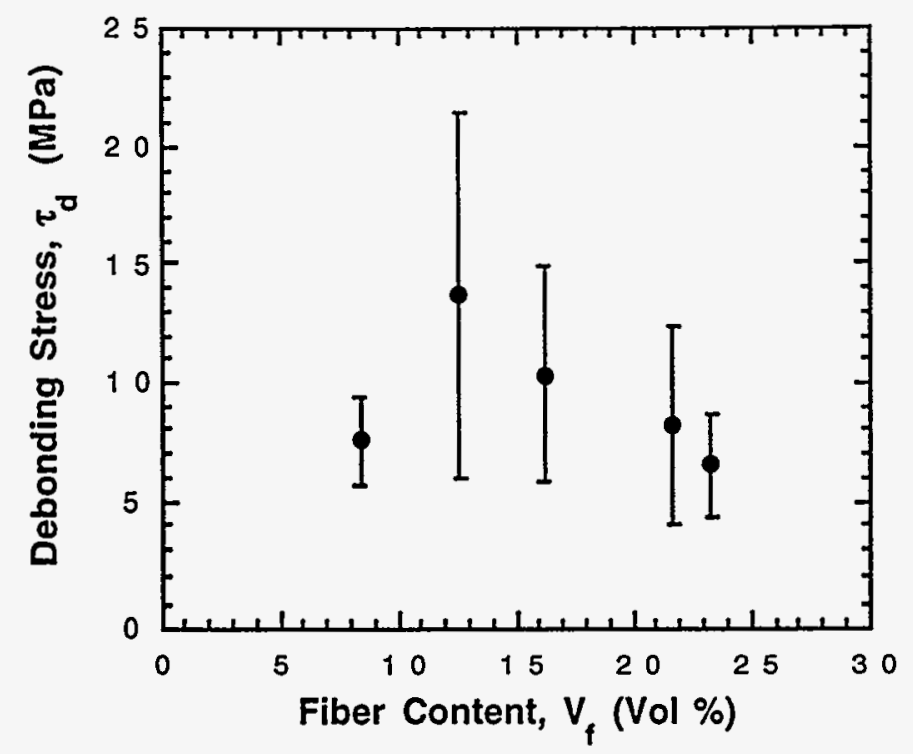

(a)

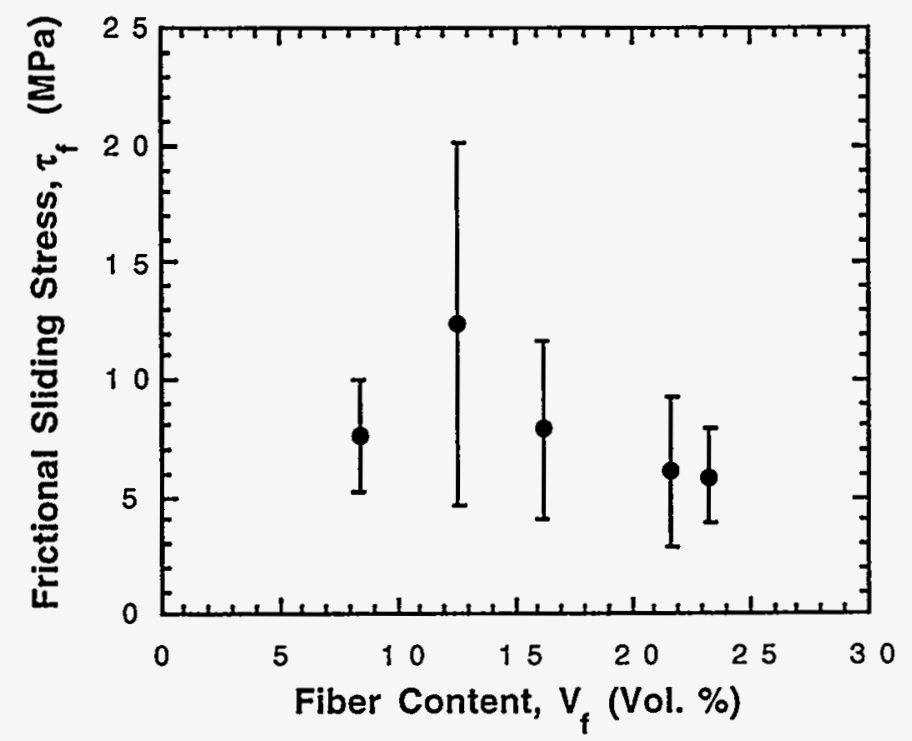

(b)

Fig 7. Variation of (a) debonding and (b) frictional sliding stresses with fiber content in $\mathrm{SiC} / \mathrm{RBSN}$ composites. 


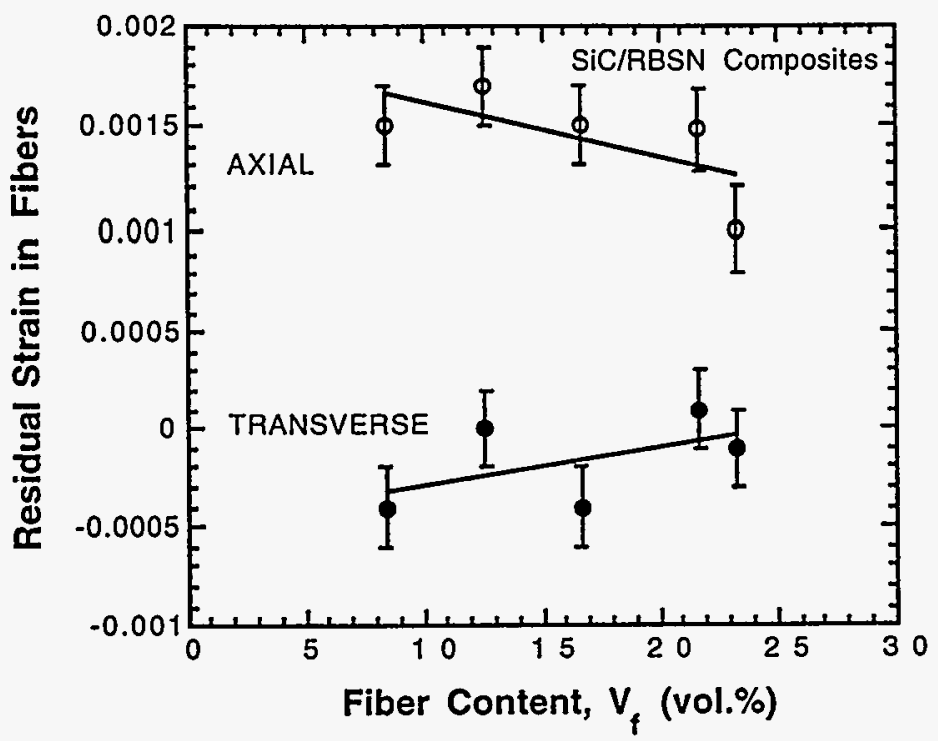

Fig. 8. Residual strain of SiC/RBSN composites as a function of fiber content, measured by neutron diffraction in the Intense Pulsed Neutron Source at Argonne National Laboratory and analytically predicted by Majumdar et al. ${ }^{14}$ (solid lines). 